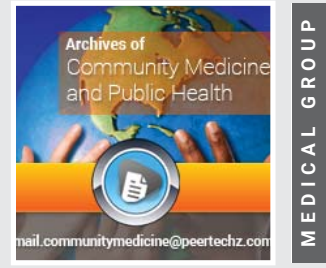

\section{Considering the effects of}

\section{mothers' economic resources}

\section{on their children's physical and psychological health}

\section{Jaewon Lee ${ }^{1 *}$ and Jennifer Allen ${ }^{2}$}

${ }^{1}$ Assistant Professor, Department of Social Welfare, Inha University, 100 Inha-ro, Michuhol-gu, Incheon 22212, South Korea

${ }^{2}$ Doctoral Student, School of Social Work, Michigan State University, Michigan
Received: 17 November, 2020

Accepted: 08 January, 2021

Published: 09 January, 2021

*Corresponding authors: Jaewon Lee, Assistant Professor, Department of Social Welfare, Inha University, 100 Inha-ro, Michuhol-gu, Incheon 22212, South Korea, Tel: 82-32-860-9324; Fax: 82-32-863-3022; E-mail: j343@inha.ac.kr

https://www.peertechz.com

Check for updates
There is a large body of studies examining parents' economic influences on their children's physical and psychological health [1-3]. However, few studies have addressed the impact of mothers' economic resources on health outcomes specifically [5-7]. Additionally, women's labor force participation is increasingly growing [7-9] and their roles in the workplace have a great impact on the labor market $[10,11]$. Thus, it is necessary to consider the influence of mothers' economic resources on their children's development, particularly regarding their physical and psychological health.

Even though gender discrimination in the labor force persists, the proportion of women's contributions to household finances is increasing compared to that of previous generations. That is, women's increased labor force participation leads to increased household income, which may allow mothers to be able to provide their children with access to better quality and more healthy food options. Given that the quality and nutritional value of foods closely relate to physical health [12-15], mothers' economic contributions through their employment positively influence their children's physical health. For instance, mothers with higher incomes, compared to those with lower incomes, may avoid providing their children with fast food $[4,16]$. As fast food consumption may lead to numerous physical health problems such as obesity, diabetes and heart disease $[14,17,18]$, it is important to reduce fast food consumption among children. In other words, mothers' economic resources inversely affect their children's fast food consumption. While fathers' economic resources are still important for children's physical health, we need to consider a new perspective regarding women's economic resources.
Moreover, economic resources are also associated with psychological health problems, such as depression and anxiety $[19,20]$. However, little is also known about the effects of mothers' economic resources on their children's psychological health. Children with wealthier parents may have more confidence in their behaviors and decisions because they are able to do things they want which require financial support. On the other hand, children who cannot receive parents' financial support may have decreased self-esteem, leading them to suffer from psychological health problems. As discussed previously, mothers' contribution at an economic level has increased [79]. Thus, we should pay more attention to mothers' economic influence on their children's psychological health.

As women's household financial contributions have increased, new research focusing on mother's economic influences has emerged [4,21,22]. However, these studies were limited to areas such as intergenerational mobility and inequality across generations. That is, there is little empirical evidence examining the effects of mothers' economic resources on their children's physical and psychological health. Therefore, we suggest that future studies should specifically consider mothers' influences to understand children's health more deeply.

\section{References}

1. Brooks-Gunn J, Duncan GJ (1997) The effects of poverty on children. Future Child 7: 55-71. Link: http://bit.ly/3hULqHN

2. Costello EJ, Compton SN, Keeler G, Angold A (2003) Relationships between poverty and psychopathology: A natural experiment. JAMA 290: 2023-2029. Link: http://bit.ly/2MQxcfH 
3. Council on Community Pediatrics (2016) Poverty and child health in the United States. Pediatrics 137: e20160339. Link: http://bit.ly/2XoCtwP

4. Lee J, Allen J (2020B) Mothers' income and young adult children's education and fast food intake. Am J Health Behav 44: 681-690. Link: http://bit.ly/2XscLHC

5. Leon M, Younger SD (2006) Transfer payments, mothers' income and child health in Ecuador. Journal of Development Studies 43: 1126-1143. Link: https://bit.ly/3hXPQOu

6. Wickham S, Whitehead M, Taylor-Robinson D, Barr B (2017) The effect of a transition into poverty on child and maternal mental health: A longitudinal analysis of the UK Millenium Cohort Study. Lancet Public Health 2: e141-e148. Link: https://bit.ly/39iQgue

7. Fernandez R (2013) Cultural change as learning: The evolution of female labor force participation over a century. American Economic Review 103: 472-500. Link: http://bit.ly/3ov39l7

8. Status of Women in the States (2020) Women's labor force participation. Link: http://bit.ly/3hXsxDW

9. Toossi M, Morisi TL (2017) Women in the workforce before, during, and after the great recession. U.S. Bureau of Labor Statistics. Link: https://bit.ly/2XnuH6z

10. Lechman E, Okonowicz A (2013) Are women important for economic development? An evidence on women's participation in labor market and their contribution to economic growth in 83 world countries. Gdansk University of Technology Faculty of Management and Economics Working Paper Series A (Economics, Management, Statistics). Link: https://bit.ly/2JXq5ki

11. Whitmore Schanzenbach D, Nunn R (2017) The 51\%: Driving growth through women's economic participation. Brookings Institution. Link: https://brook.gs/3ntJabm

12. An R (2016) Fast-food and full-service restaurant consumption and daily energy andnutrient intakes in US adults. Eur J Clin Nutr 70: 97-103. Link: http://bit.ly/38pN6Wz

13. Bowman SA, Gortmaker SL, Ebbeling CB, Pereira MA, Ludwig DS (2004)
Effects of fast-food consumption on energy intake and diet quality among children in a national household survey. Pediatrics 113: 112-118. Link: http://bit.ly/2LzPL7a

14. Chandran U, McCann SE, Zirpoli G, Gong Z, Lin Y, et al. (2014) Intake of energydense foods, fast foods, sugary drinks, and breast cancer risk in African American and European American women. Nutr Cancer 66: 1187-1199. Link: http://bit.ly/39cJhmN

15. Fiolet T, Srour B, Sellem L, Kesse-Guyot E, Alles B, et al. (2018) Consumption of ultra-processed foods and cancer risk: Results from NutriNet-Santé prospective cohort. BMJ 360: k322. Link: http://bit.ly/3s5okmh

16. Watts AW, Mason SM, Loth K, Larson N, Neumark-Sztainer D (2016) Socioeconomic differences in overweight and weight-related behaviors across adolescence and young adulthood: 10-year longitudinal findings from Project EAT. Preventive Medicine 87: 194-199. Link: http://bit.ly/3nt9l26

17. Bahadoran Z, Mirmiran P, Azizi F (2015) Fast food pattern and cardiometabolic disorders: A review of current studies. Health Promot Perspect 5: 231-240. Link: http://bit.ly/3otoQZI

18. Bowman SA, Vinyard BT (2003) Fast food consumption of U.S. adults: Impact on energy and nutrient intakes and overweight status. J Am Coll Nutr 23: 163168. Link: http://bit.ly/35nN0wu

19. Lee J, Allen J (2020D) Young adults' economic well-being and mental health: The mediation model of self-esteem. The American Journal of Psychology 133: 329-339

20. Najman JM, Hayatbakhsh MR, Clavarino A, Bor W, O'Callaghan MJ, et al (2010) Family poverty over the early life course and recurrent adolescent and young adult anxiety and depression: A longitudinal study. Am J Public Health100: 1719-1723. Link: http://bit.ly/399Q2pq

21. Lee J, Allen J (2020A) Mother's educational attainment and their young adult daughters' fast food intake: The role of race/ethnicity. Health Care Women Int 41: 169-187. Link: http://bit.ly/3hXrAeQ

22. Lee J, Allen J (2020C) The intergenerational transmission of income mobility between mothers and their young adult daughters: The mediating role of their daughters' educational attainment. Social Policy \& Administration 54. Link: https://bit.ly/38q2MZM

\section{Discover a bigger Impact and Visibility of your article publication with}

\section{Peertechz Publications}

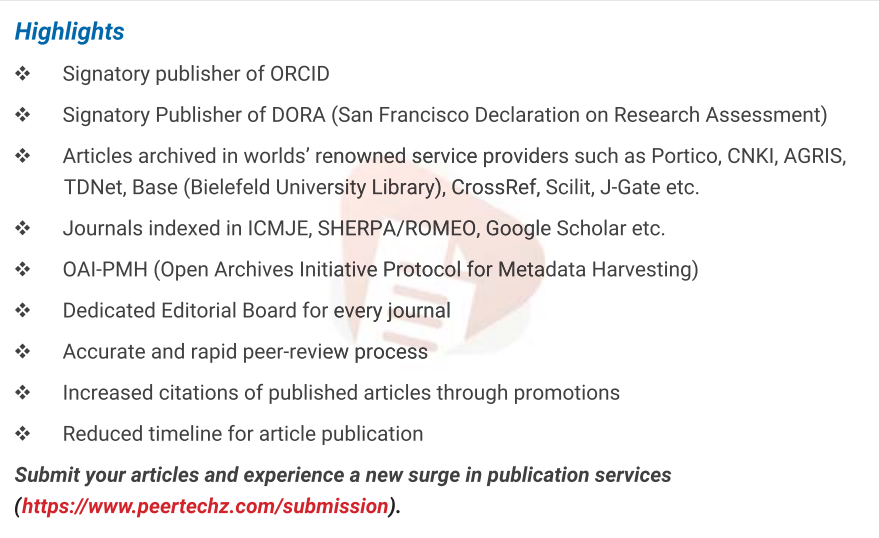

Peertechz journals wishes everlasting success in your every endeavours.

Copyright: () 2021 Lee J, et al. This is an open-access article distributed under the terms of the Creative Commons Attribution License, which permits unrestricted use, distribution, and reproduction in any medium, provided the original author and source are credited.

Citation: Lee J, Allen J (2021) Considering the effects of mothers' economic resources on their children's physical and psychological health. Arch Community Med Public Health 7(1): 006-007. DOI: https://dx.doi.org/10.17352/2455-5479.000124 